\title{
Loudness and reaction time: I
}

\author{
DAVID L. KOHFELD, JEFFREY L. SANTEE, and NORVAL D. WALLACE \\ Southern Illinois University, Edwardsville, Illinois 62026
}

\begin{abstract}
It is widely assumed, based on Chocholle's (1940) research, that stimuli that appear equal in loudness will generate the same reaction times. In Experiment 1, we first obtained equal-loudness functions for five stimulus frequencies at four different intensity levels. It was found that equal loudness produced equal RT at 80 phons and 60 phons, but not at 40 phons and 20 phons. It is likely that Chocholle obtained equivalence between loudness and RT at all intensity levels be cause of relay-click transients in his RT signals. One main conclusion drawn from Experiment 1 is that signal detection (in reaction time) and stimulus discrimination (in loudness estimation) require different perceptual processes. In the second phase of this investigation, the RT-intensity functions from six different experiments were used to generate scales of auditory intensity. Our analyses indicate that when the nonsensory or "residual" component is removed from auditory RT measures, the remaining sensory-detection component is inversely related to sound pressure according to a power function whose exponent is about -.3. The absolute value of this exponent is the same as the .3 exponent for loudness when interval-scaling procedures are used, and is one-half the size of the .6 exponent which is commonly assumed for loudness scaling.
\end{abstract}

The historic traditions that underlie the present research are formidable. Psychophysicists have consistently found a direct relation between auditory stimulus intensity and loudness. Specifically, Stevens and his colleagues have established that perceived loudness grows as a power function of stimulus intensity (Marks, 1974, 1979). Equally impressive is the evidence in support of an inverse relation between stimulus intensity and simple auditory reaction time (RT). Classic experiments by Cattell (1886), Chocholle (1940), Pieron (1920), and Wundt (1874) have convincingly shown that RT decreases monotonically with corresponding increases in auditory stimulus intensity.

Based on the fact that stimulus frequency, along with stimulus intensity, are the primary determinants of both loudness and RT, the present paper comprises two major sections in which these two stimulus attributes are evaluated. First, we evaluated the relation between equal loudness (across frequencies) and RT, using Chocholle's (1940) research as the point of departure for Experiment 1. In Phase 2, we

This research was supported by Research Grant 93614 to D. L. Kohfeld and N. D. Wallace, and by a Summer Research Fellowship awarded to D. L. Kohfeld. All of these funds came from the Office of Research and Projects in the Graduate School at Southern Illinois Unjversity, Edwardsville. Robert Ruhl provided the instrumentation for this research. Data collection for Experiment 2 was supported in part by NSF Grant BNS-76-01227 to H. Egeth and J. Pomerantz. J. L. Santee is now at The Johns Hopkins University. We are grateful to Edward C. Carterette, R. Duncan Luce, and Bertram Scharf for their careful reviews and constructive criticisms of earlier drafts of this paper; however, we are responsible for the final version of this article. Requests for reprints should be sent to David L. Kohfeld, Department of Psychology, Southern Illinois University at Edwardsville, Edwardsville, Illinois 62026. attempted to synthesize the data from several RT experiments in order to construct a uniform scale of sensory intensity that is based on RT measures.

\section{PHASE 1: EQUAL LOUDNESS AND REACTION TIME}

It is remarkable how many investigators have cited Chocholle's research, conducted over $\mathbf{4 0}$ years ago at the Sorbonne Laboratory, as the definitive study of the relation between auditory RT and signal intensity and frequency. His experiments were extensive but simple in design. Three experienced subjects generated RT-intensity functions over a wide range of intensity levels for frequencies of $20,50,250,500$, $1,000,2,000,4,000,6,000$, and $10,000 \mathrm{~Hz}$. From these initial results, he drew "equal-RT" contours; that is, stimulus intensity (in $\mathrm{dB}, \mathrm{SL}$, at each frequency) was plotted against stimulus frequency $(\mathrm{Hz})-$ the data points were equal RT values (in msec) across frequencies. Chocholle noted that his equal-RT curves were "similar in many ways to the equal-loudness curves, plotted as a function of the frequency and of the intensity levels above the threshold, reported by Fletcher and Munson in 1933" (Chocholle, 1940, p. 82). ${ }^{1}$ Following this, Chocholle obtained individual equal-loudness contours from each of his subjects at the same frequencies as before. The stimuli of equal loudness for each subject were then presented as RT signals to that subject. As before, the main findings were that (1) RT systematically decreased with a corresponding increase in signal intensity, and (2) equally loud stimuli produced equal RTs regardless of stimulus frequency. 
The popularity enjoyed by Chocholle's classic work is well deserved, especially in view of the orderliness of the RT-intensity functions for the nine different signal frequencies. As such, the data were particularly suitable for subsequent curve-fitting analyses (Woodworth \& Schlosberg, 1954), and more recently, the scaling of auditory intensity (Luce \& Green, 1972; Marks, 1974; McGill, 1961; Restle, 1961). Moreover, the inverse relation between RT and stimulus intensity obtained by Chocholle (especially at $1,000 \mathrm{~Hz}$ ) has been replicated in virtually every subsequent investigation in which signal intensity has been included as a variable in the RT paradigm.

Why then, did we undertake the replication of Chocholle's research? One reason was that the relation between RT and signal frequencies of equal loudness obtained by Chocholle has not received much attention, and perhaps has not been replicated. Second, a recent investigation by Santee and Kohfeld (1977) revealed that the relation between loudness and RT may not be as clear-cut as is commonly assumed. Santee and Kohfeld first obtained equalloudness data for 100-, 1,000-, and $10,000-\mathrm{Hz}$ tones at intensity levels of $20,40,60$, and 80 phons. It was anticipated that equally loud stimuli would then produce equivalent RTs at the three different signal frequencies. Somewhat surprisingly, we found a substantial Signal Frequency by Signal Intensity interaction in the RT measures. As predicted, the RTfrequency functions were flat for the 80- and 60-phon intensity levels, but at 40 phons, and especially at 20 phons, substantially longer RTs were obtained from $1,000-\mathrm{Hz}$ signals than from either the 100 - or $10,000-\mathrm{Hz}$ tones. In other words, equally loud stimuli yielded equal RTs if strong-intensity signals were used, but not when relatively weak-intensity levels were presented. In view of the discrepancy between Santee and Kohfeld's data and those of Chocholle, particularly at the weak-intensity levels, we considered it important to conduct the present experiment in which a wider range of frequencies, a larger number of subjects, and more RT measures per subject were included in the design.

A third reason for the present Experiment 1 can be traced to our French-to-English translation of Chocholle's original article. Specifically, in a section entitled "Measurement Technique" (pp. 70-80), Chocholle noted that he had difficulties with the highamplitude click transients associated with the gating of the auditory signals through the electromagnetic earphone he used. To quote from one paragraph in Chocholle:

The problem of (click) transients is another difficulty .... I think it possible that the clicks which occur when an (electromagnetic) earphone is used can be attrib- uted, at least in part, to the very sudden contact of the diaphragm against the electromagnet when the attraction is so forceful .... The clicks are clearly audible only at strong stimulus intensities, and they are more intense as the frequency of the current which is applied to the earphone becomes farther from the middle frequencies. It is impossible to suppress the clicks. Of course, it would be possible to diminish the clicks by adding appropriate capacitance and resistance to the circuit, but this would have the undesired effect of reducing the intensity of the current, except for measures which are just above threshold. It is true that the subjects have sometimes been annoyed by the clicks, particularly at high and low frequencies. However, the clicks are clearly distinguishable at the onset of the auditory signal, since their subjective intensity is different. On the one hand, if the clicks are subjectively weaker than the auditory signal, they are perceived as occurring after the auditory signal. On the other hand, if the clicks sound stronger than the actual signal (which occurs while taking slightly supraliminary measures at the extreme frequencies), the clicks seern to occur before the auditory signal .... But a practiced subject can easily disregard the clicks, since he has learned to anticipate the actual auditory signal, and does not have to pay attention to the clicks. (pp. 72-73)

We are not confident that subjects can successfully disregard the sound of a "noisy" switching device, and it is possible that click transients contribute to the signal energy of a pure tone (Richards, 1976, p. 61). Unfortunately, Chocholle did not have available a more contemporary method for gating auditory signals, that is, an electronic switch with controllable rise and decay times. Our present experiment included a condition in which relay clicks were deliberately introduced into the RT signals. In this way, the effects on RT of relay-click transients were evaluated by comparing the data from a click-present condition with those obtained in click-free conditions.

\section{EXPERIMENT 1}

\section{Method}

Equal-loudness matching. The subjects were two graduate students, aged 25 and 26 years, one 24-year-old undergraduate, and one 18-year-old high school student. All four students were males, and all possessed normal hearing thresholds $\left(20 \mu \mathrm{N} / \mathrm{m}^{2}\right.$ at 1,000 $\mathrm{Hz}$ ). Each subject had had some previous experience in the equalloudness matching and RT procedures.

Equal-loudness matches were obtained while the subject sat in a sound-attenuated booth. Alternating bursts of the standard and comparison tones were generated by means of separate audio oscillators. A Grason-Stadler Model 1287B electronic switch gated each tone for $2.5 \mathrm{sec}$ with a rise and decay time of $10 \mathrm{msec}$. Two adjustable attenuators were located outside the booth, and were controlled by the experimenter. Each subject was tested individually. Communication between subject and experimenter was by means of an intercom system. The tones were presented monaurally through a pair of TDH-39 headphones, calibrated in a NBS-9A coupler. Throughout each session, the voltage across each earphone was monitored and carefully calibrated. Specifically, the subject's task was to match subjectively the loudnesses of alter- 
nating bursts of a $1,000-\mathrm{Hz}$ tone (left ear) at a standard intensity with a comparison tone (right ear) at a variable intensity. The experimenter adjusted the attenuation of the comparison tone whenever instructed to do so by the subject (i.e., "up" or “down").

Each subject's absolute threshold for a $1,000-\mathrm{Hz}$ tone was determined by using a method of limits. Subsequently, the equalloudness matches were conducted over four daily experimental sessions, 1 day for each of the 20-, 40-, 60-, and 80-phon intensity levels. A daily session included matches for each of the stimulus frequencies in the following order: $5,000,100,10,000$, and $500 \mathrm{~Hz}$. The subject was presented the alternating stimuli at a given intensity (re sensation level for $1,000-\mathrm{Hz}$ tone) in a session, and he matched the comparison tone with the loudness of the $1,000-\mathrm{Hz}$ standard tone by instructing the experimenter to increase or decrease the intensity of the comparison tone in steps of $1 \bullet \mathrm{dB}$. A few practice trials were provided whenever the frequency of the comparison tone was changed, thus allowing the subject to become adapted to a change in pitch before making any loudness judgments. Prior to each loudness match, the differences in intensity between the standard and comparison tones was set arbitrarily by the experimenter. Each subject made 10 matches at each combination of intensity and frequency: five increasing adjustments (comparison with standard intensity) and five decreasing adjustments. Although an equal number of increasing and decreasing adjustments were made, the subjects sometimes overshot the desired point of subjective equality (PSE) between the standard and comparison tones. In such cases, they were allowed to bracket the PSE until they were completely satisfied. The subjects were allowed to take as much time as necessary to make their loudness matches. That is, they were neither prompted as to when they should make their judgments nor provided any feedback as to when the change in attenuation would be made by the experimenter.

Reaction-time procedures. The same four subjects were employed in the RT tasks. The RT sessions were also conducted in the sound-attenuated booth. The response signals were generated by an audio oscillator, then adjusted for intensity by a decade attenuator, and then gated through the same electronic switch that was used for the equal-loudness matching. The rise and decay time also remained at $10 \mathrm{msec}$. On each trial, a weak-intensity white light with a duration of $1 \mathrm{sec}$ served as the ready signal, followed by a 1-sec foreperiod interval. A response signal was then presented binaurally through the same set of calibrated headphones that was used in the equal-loudness matching. As soon as the subject pressed the response button, the response signal was terminated. The intertrial interval was $1 \mathrm{sec}$. Response signal frequencies and intensities were adjusted manually prior to each RT session. The timing of events was controlled by means of a programmed sequence that was punched on plastic tapes and read through a system of solid-state logic. RT was recorded in milliseconds by a digital, printout counter.

A Donders Type $\mathbf{C}$ method of stimulus presentation was employed such that the subject responded as quickly as possible upon detection of the RT signal (a "go" trial) and withheld a response when no signal appeared (a "catch" trial). Each RT session consisted of six blocks of trials (32 RT trials per block), and each block could be initiated by the subject from inside the sound booth. In the 32 trials per block, the presentation order of the 24 go trials and 8 catch trials was randomized in order to prevent the anticipation of a RT signal. Six blocks, or 144 RT scores, were obtained from each subject in each of the 20 frequency-phons stimulus conditions, thus yielding a total of 2,880 RT measures per subject across all conditions.

Two additional blocks of RT trials ( 48 measures) were obtained from one subject at each of the five frequencies at 20 phons. In these trials, transient clicks associated with the onset of the RT signals were implemented by bypassing the electronic switch with a CP Clare, HGSM 1010 relay with mercury-wetted contacts, as provided in a RY-205 BRS/LVE solid-state module. Using an oscilloscope, we found that this relay, when actuated, takes about $50 \mu \mathrm{sec}$ to change a signal from the unloaded to the loaded (attenuated) state at the particular amplitude of a signal (in its frequency cycle) when it is "gated." Due to equipment limitations, it was not possible to measure the actual spectrum of this relay across the earphones that were used in our research.

RT scores were generated from signal levels obtained in each of the intensity-frequency combinations that were measured in the equal-loudness matching, thus creating a 20-cell factorial design: 4 intensities $(20,40,60$, and 80 phons) by 5 frequencies $(100,500$, $1,000,5,000$, and $10,000 \mathrm{~Hz}$ ). It is important to note that the intensities (phons) of the response signals for each subject varied in accordance with his particular equal-loudness matching values. All subjects were given the $\mathbf{2 0}$ stimulus conditions in a different, but random, order. Prior to data collection, a short practice period of approximately 10 trials was provided whenever a change was made in any one of the stimulus parameters.

No errors were permitted. Thus, if a subject responded on a catch trial, that entire block of trials was immediately terminated, and the taped program resumed with the next programmed block. The incidence of errors (block terminations) was so negligible that a tabulation of error data was not practical; that is, about one block in nine required termination because of a single "catch," thus yielding an overall error rate that was less than $1 \%$. This was mainly because the four subjects involved in this experiment had extensive practice with the Donders Type $C$ paradigm prior to the collection of the RT measures that were used in this research.

\section{Results}

Equal-loudness contours. All four subjects had sensation levels of approximately $20 \mu \mathrm{N} / \mathrm{m}^{2}$ (SPL) for the $1,000-\mathrm{Hz}$ tone. Using this intensity as the 0 -dB reference, equal-loudness data are plotted in Figure 1 with stimulus intensity on the ordinate and stimulus frequency on the abscissa. Each point in Figure 1 represents the mean of $\mathbf{4 0}$ loudness matches (10/subject) between the $1,000-\mathrm{Hz}$ standard and the various comparison tones. The lines that connect the data points for each of the four levels of intensity form equal-loudness contours, indicating the changes in intensity that are required for loudness to remain constant across the different frequencies.

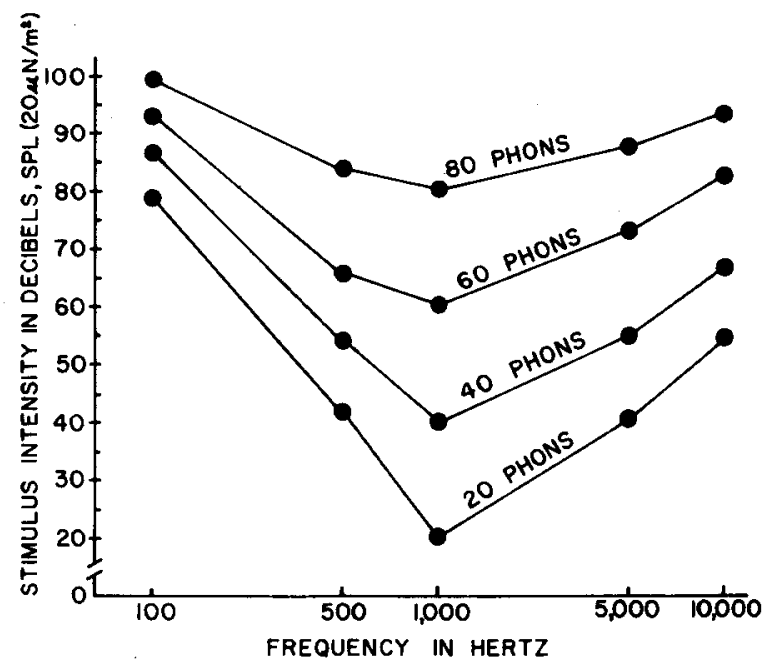

Figure 1. Plot of the stimulus intensities (in dB, SPL) necessary to produce equal loudness (in phons) across five stimulus frequencies. The 1,000-Hz tone served as the standard for the equal loudness matches. 
Table 1

Means and Standard Deviations of the Equal-Loudness Matches (in Decibels) Obtained for Each Subject, and Across Subjects in Each Condition

\begin{tabular}{|c|c|c|c|c|c|c|c|c|}
\hline \multirow[b]{3}{*}{ Subject } & \multicolumn{8}{|c|}{ Phons } \\
\hline & \multicolumn{2}{|c|}{20} & \multicolumn{2}{|c|}{40} & \multicolumn{2}{|c|}{60} & \multicolumn{2}{|c|}{80} \\
\hline & Mean & SD & Mean & SD & Mean & SD & Mean & SD \\
\hline & \multicolumn{8}{|c|}{$100 \mathrm{~Hz}$} \\
\hline J.S. & 79.70 & 1.06 & 89.60 & .97 & 92.70 & 1.34 & 95.30 & .67 \\
\hline C.S. & 74.40 & .84 & 87.10 & 1.20 & 93.70 & 1.34 & 102.30 & 1.89 \\
\hline J.R. & 81.60 & .84 & 84.30 & .95 & 91.60 & .84 & 93.80 & 1.14 \\
\hline O.M. & 79.90 & 1.10 & 86.40 & .70 & 94.80 & .92 & 104.60 & 1.96 \\
\hline \multirow[t]{2}{*}{ Overall } & 78.90 & 2.89 & 86.85 & 2.13 & 93.20 & 1.62 & 99.00 & 4.83 \\
\hline & \multicolumn{8}{|c|}{$500 \mathrm{~Hz}$} \\
\hline J.S. & 36.90 & .99 & 43.30 & 1.25 & 62.80 & 1.93 & 78.70 & .95 \\
\hline C.S. & 33.40 & 1.65 & 50.30 & .95 & 60.50 & 1.43 & 82.10 & 1.29 \\
\hline J.R. & 50.70 & .67 & 62.40 & 1.07 & 71.20 & .79 & 83.60 & 1.26 \\
\hline $\mathrm{O} . \mathrm{M}$ & 49.10 & .88 & 60.90 & .57 & 68.70 & 1.16 & 92.70 & 2.00 \\
\hline \multirow[t]{2}{*}{ Overall } & 42.52 & 7.67 & 54.22 & 8.00 & 65.80 & 4.57 & 84.27 & 5.42 \\
\hline & \multicolumn{8}{|c|}{$5,000 \mathrm{~Hz}$} \\
\hline J.S. & 40.80 & 1.40 & 49.70 & 1.25 & 64.10 & .74 & 80.30 & 1.77 \\
\hline C.S. & 19.80 & 1.40 & 44.70 & 4.45 & 69.20 & 1.14 & 89.40 & 1.43 \\
\hline J.R. & 53.20 & 2.10 & 60.70 & .82 & 78.10 & 1.73 & 89.50 & 1.58 \\
\hline O.M. & 48.40 & 1.58 & 65.90 & 1.04 & 82.20 & .92 & 90.30 & .82 \\
\hline \multirow[t]{2}{*}{ Overall } & 40.55 & 13.03 & 55.25 & 10.23 & 73.40 & 7.31 & 87.37 & 4.37 \\
\hline & \multicolumn{8}{|c|}{$10,000 \mathrm{~Hz}$} \\
\hline J.S. & 49.00 & 1.76 & 59.50 & 1.84 & 72.30 & 1.06 & 84.00 & 1.25 \\
\hline C.S. & 38.40 & 1.35 & 56.20 & 5.60 & 79.60 & 1.07 & 92.20 & 1.32 \\
\hline J.R. & 68.60 & .97 & 69.70 & 1.49 & 90.00 & 1.63 & 96.50 & .71 \\
\hline O.M. & 63.90 & 1.20 & 81.80 & 1.23 & 89.10 & .74 & 100.40 & 1.90 \\
\hline Overall & 54.98 & 11.89 & 66.80 & 10.65 & 82.75 & 7.45 & 93.26 & 6.30 \\
\hline
\end{tabular}

Note-1,000 $\mathrm{Hz}$ was the standard frequency for the equal-loudness matches.

In addition, Table 1 presents both the intra- and intersubject means and standard deviations obtained during the loudness-matching procedures. From this table, it can be seen that each subject produced remarkably consistent equal-loudness judgments, particularly in view of the fact that Steinberg and Munson (1936) have reported that it is not unusual for the standard deviation of a single subject to average as high as $\pm 7 \mathrm{~dB}$. However, the low intrasubject variability in our data may be partially due to the fact that each subject performed 10 consecutive equalloudness matches at a given frequency and intensity; for example, five increasing adjustments and five decreasing adjustments, presented randomly, provided the data for Subject J.S. at $100 \mathrm{~Hz}, 20$ phons. The overall (intersubject) variability at each of the frequency-intensity conditions, as would be expected, is somewhat higher and is indicative of the individual differences that are typically found in the equalloudness literature (e.g., Robinson \& Dadson, 1956; Ross, 1967; Steinberg \& Munson, 1936).

The equal-loudness contours in Figure 1 indicate that (1) progressively stronger stimulus intensities (in $\mathrm{dB}$ ) are required for loudness (in phons) to remain constant as frequencies either rise or fall from 1,000
$\mathrm{Hz}$, and that (2) separation of the contours reaches a minimum at the low end of the frequency axis, whereas the maximum separation of the curves occurs at $1,000 \mathrm{~Hz}$. The data are consistent with previous research in which the contours became progressively flatter as stimulus intensity was increased. In other words, loudness is a function of both stimulus intensity and frequency, such that the role of stimulus frequency decreases as stimulus intensity increases.

Although the contours shown in Figure 1 reveal the same general trends as those reported in previous equal-loudness research, our curves are steeper than those reported by Molino (1973) and Ross (1967), particularly at the low end of the frequency axis. This discrepancy may be accounted for by the different calibration procedures used in the various studies. The earphones in the present study were calibrated with a coupler, whereas Ross (1967), for example, recorded signal intensity from the ear canal of his subjects. Several investigators have noted that for low frequencies, such as $100 \mathrm{~Hz}$, the SPL in the ear canal is approximately $12-16 \mathrm{~dB}$ lower than in the coupler for the same level of input to the earphones (e.g., Beranek, 1949; Hellman \& Zwislocki, 1968). 
This is due to leakage between the ear and the cushion of the earphone, which becomes insignificant for frequencies above $200 \mathrm{~Hz}$.

Our equal-loudness contours are also considerably steeper than those reported in the classic studies conducted by Fletcher and Munson (1933) and Robinson and Dadson (1956). This discrepancy is probably based on the fact that our tones were presented through calibrated earphones, whereas Fletcher and Munson and Robinson and Dadson provided data that were based on free-field (speaker) presentations. ${ }^{2}$

The factors that contribute to the relative flatness of the equal-loudness contours reported in free-field studies, as compared with the data from earphone experiments, have not been clearly identified. However, Ross (1967) has suggested that low-frequency distortions in the signals may flatten the contours obtained with free-field methods. Shallower slopes could also result from the fact that less intense levels of "physiological noise" are present at low frequencies in free-field conditions (that is, the free-field speakers against which the tones in Fletcher and Munson's study were calibrated), in comparison with the earphone presentations employed more recently.

In conclusion, there are advantages to each method of obtaining equal-loudness judgments (earphones vs. speakers), depending on one's purposes. The freefield method resembles normal listening conditions, whereas the audible pressure method (i.e., with headphones) more closely simulates the conditions that are usually employed in auditory reaction-time tasks in which precise gating of the RT signals is desired. Thus, if one's goal is to obtain RT-frequency curves, we think that it would be undesirable to use RT signals, presented through earphones, whose intensity levels were selected from previous (free-field) equalloudness data. Indeed, a post hoc finding in our laboratory revealed that when the decibel (SPL) values obtained from either Fletcher and Munson's or Robinson and Dadson's curves at 20 phons were presented through earphones, our subjects could not detect the onset of the 20-phon signals at 100,5,000, and $10,000 \mathrm{~Hz}$. Clearly, future research which involves a comparison of equal-loudness contours with RT-frequency curves may benefit from two methodological suggestions: (1) The method of stimulus presentation (earphone vs. speaker) should be the same in both the equal-loudness and the reactiontime phases of the experiment; and (2) the subjects who serve in the reaction-time phase should generate their own, individual equal-loudness curves from which the corresponding RT signals are selected for each person.

RT-frequency functions. Figure 2 depicts mean RT as a function of signal intensity (phons) and frequency $(\mathrm{Hz})$. Each point represents the mean of 576 RT trials (144 per subject). The lines that connect these data points yield four "RT-frequency" functions. Although the mean RT measures in these func-

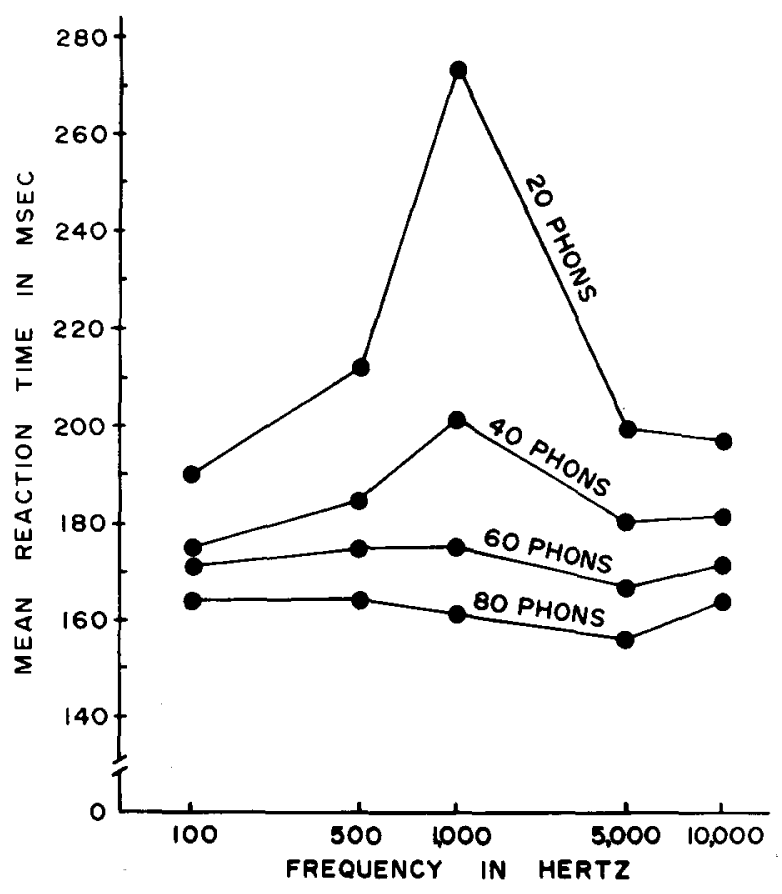

Figure 2. Mean reaction time as a function of stimulus frequency (Hz) at four levels of loudness (phons). Each of the data points represents the mean of 576 RT measures.

tions were averaged across subjects, each subject's RT scores were obtained in response to the signals generated from his individual equal-loudness judgments.

Several aspects of Figure 2 deserve comment. First, it is clear that RT was inversely related to signal intensity, as found in numerous other investigations. Second, if equal loudness generates equal-RT measures, all four of the RT-frequency functions in Figure 2 should be approximately flat, except for slight, random fluctuations. It is apparent, however, that at the 20- and 40-phon intensity levels, equally loud tones did not produce equivalent RTs across the signal frequencies. This is because at the two lower levels of intensity, RTs to the $1,000-\mathrm{Hz}$ tones were substantially longer than those to the other frequency values (see, also, Santee \& Kohfeld, 1977). Third, the effects of signal frequency appeared to be negligible at the 60- and 80-phon intensity levels, in comparison with the two lower levels of intensity, a result which suggests a possible interaction between stimulus intensity and frequency.

In support of these interpretations are the results of a 4 (phons) by $5(\mathrm{~Hz})$ repeated-measures analysis of variance, which provided the following significant effects: Stimulus Intensity, $F(3,9)=31.94, p<.001$; Stimulus Frequency, $F(4,12)=13.33, p<.001$; and Intensity by Frequency, $F(12,36)=13.81, p<.001$. The stimulus factors of intensity and frequency and the interaction of frequency with intensity accounted for $53 \%, 14 \%$, and $20 \%$, respectively, of the total variance in the RT measures. The remaining $13 \%$ of the 
Table 2

Means and Standard Deviations (SDs) of the Reaction Time Measures (in Milliseconds)

Obtained for Each Subject, and Across Subjects in Each Condition

\begin{tabular}{|c|c|c|c|c|c|c|c|c|}
\hline \multirow[b]{3}{*}{ Subject } & \multicolumn{8}{|c|}{ Phons } \\
\hline & \multicolumn{2}{|c|}{20} & \multicolumn{2}{|c|}{40} & \multicolumn{2}{|c|}{60} & \multicolumn{2}{|c|}{80} \\
\hline & Mean & SD & Mean & SD & Mean & $\mathrm{SD}$ & Mean & SD \\
\hline & \multicolumn{8}{|c|}{$100 \mathrm{~Hz}$} \\
\hline $\begin{array}{l}\text { J.S. } \\
\text { C.S. } \\
\text { J.R. } \\
\text { O.M. }\end{array}$ & $\begin{array}{l}176.62 \\
201.26 \\
191.63 \\
189.60\end{array}$ & $\begin{array}{l}15.00 \\
13.42 \\
17.70 \\
17.56\end{array}$ & $\begin{array}{l}162.70 \\
181.66 \\
172.94 \\
183.13\end{array}$ & $\begin{array}{l}14.76 \\
12.55 \\
14.65 \\
17.93\end{array}$ & $\begin{array}{l}161.89 \\
172.95 \\
171.62 \\
176.11\end{array}$ & $\begin{array}{l}14.18 \\
11.41 \\
16.80 \\
16.60\end{array}$ & $\begin{array}{l}153.21 \\
164.80 \\
166.43 \\
172.55\end{array}$ & $\begin{array}{l}15.29 \\
11.33 \\
18.03 \\
15.57\end{array}$ \\
\hline \multirow[t]{2}{*}{ Overall } & 189.78 & 18.43 & 175.11 & 17.43 & 170.64 & 15.90 & 164.25 & 17.06 \\
\hline & \multicolumn{8}{|c|}{$500 \mathrm{~Hz}$} \\
\hline $\begin{array}{l}\text { J.S. } \\
\text { C.S. } \\
\text { J.R. } \\
\text { O.M. }\end{array}$ & $\begin{array}{l}200.73 \\
228.48 \\
214.46 \\
204.32\end{array}$ & $\begin{array}{l}20.00 \\
18.86 \\
16.30 \\
18.01\end{array}$ & $\begin{array}{l}175.79 \\
191.64 \\
177.92 \\
195.69\end{array}$ & $\begin{array}{l}14.08 \\
15.01 \\
17.74 \\
16.23\end{array}$ & $\begin{array}{l}165.95 \\
183.76 \\
165.51 \\
184.45\end{array}$ & $\begin{array}{l}14.03 \\
11.86 \\
20.52 \\
15.72\end{array}$ & $\begin{array}{l}152.84 \\
166.46 \\
158.24 \\
177.26\end{array}$ & $\begin{array}{l}12.39 \\
12.47 \\
11.84 \\
16.62\end{array}$ \\
\hline \multirow[t]{2}{*}{ Overall } & 212.00 & 21.51 & 185.26 & 17.69 & 174.92 & 17.92 & 163.70 & 16.20 \\
\hline & \multicolumn{8}{|c|}{$1,000 \mathrm{~Hz}$} \\
\hline $\begin{array}{l}\text { J.S. } \\
\text { C.S. } \\
\text { J.R. } \\
\text { O.M. }\end{array}$ & $\begin{array}{l}218.21 \\
298.56 \\
323.93 \\
252.68\end{array}$ & $\begin{array}{l}23.49 \\
39.51 \\
44.49 \\
22.04\end{array}$ & $\begin{array}{l}177.58 \\
204.03 \\
208.94 \\
212.90\end{array}$ & $\begin{array}{l}16.42 \\
13.80 \\
17.64 \\
17.84\end{array}$ & $\begin{array}{l}165.45 \\
179.96 \\
177.57 \\
178.48\end{array}$ & $\begin{array}{l}12.83 \\
13.28 \\
16.51 \\
19.36\end{array}$ & $\begin{array}{l}156.87 \\
160.62 \\
166.99 \\
160.43\end{array}$ & $\begin{array}{l}16.98 \\
12.30 \\
23.17 \\
15.10\end{array}$ \\
\hline \multirow[t]{2}{*}{ Overall } & 273.34 & 53.34 & 200.86 & 22.60 & 175.36 & 16.53 & 161.23 & 17.67 \\
\hline & \multicolumn{8}{|c|}{$5,000 \mathrm{~Hz}$} \\
\hline $\begin{array}{l}\text { J.S. } \\
\text { C.S. } \\
\text { J.R. } \\
\text { O.M. }\end{array}$ & $\begin{array}{l}175.24 \\
215.44 \\
206.62 \\
198.63\end{array}$ & $\begin{array}{l}15.80 \\
16.70 \\
20.47 \\
22.09\end{array}$ & $\begin{array}{l}165.20 \\
187.70 \\
174.73 \\
193.37\end{array}$ & $\begin{array}{l}14.60 \\
14.88 \\
17.40 \\
17.15\end{array}$ & $\begin{array}{l}160.66 \\
168.78 \\
167.28 \\
173.21\end{array}$ & $\begin{array}{l}15.39 \\
11.75 \\
17.75 \\
16.15\end{array}$ & $\begin{array}{l}152.44 \\
155.95 \\
156.26 \\
158.31\end{array}$ & $\begin{array}{l}15.97 \\
10.99 \\
12.58 \\
15.10\end{array}$ \\
\hline \multirow[t]{2}{*}{ Overall } & 198.98 & 24.61 & 180.25 & 19.55 & 167.48 & 16.16 & 155.74 & 14.45 \\
\hline & \multicolumn{8}{|c|}{$10,000 \mathrm{~Hz}$} \\
\hline $\begin{array}{l}\text { J.S. } \\
\text { C.S. } \\
\text { J.R. } \\
\text { O.M. }\end{array}$ & $\begin{array}{l}179.07 \\
203.02 \\
204.56 \\
202.20\end{array}$ & $\begin{array}{l}21.36 \\
17.11 \\
18.53 \\
20.08\end{array}$ & $\begin{array}{l}173.08 \\
182.32 \\
181.92 \\
188.83\end{array}$ & $\begin{array}{l}17.27 \\
14.25 \\
19.45 \\
19.75\end{array}$ & $\begin{array}{l}159.85 \\
167.95 \\
174.37 \\
187.60\end{array}$ & $\begin{array}{l}15.97 \\
13.61 \\
15.25 \\
15.44\end{array}$ & $\begin{array}{l}155.36 \\
162.84 \\
169.56 \\
168.94\end{array}$ & $\begin{array}{l}15.70 \\
11.84 \\
14.86 \\
14.85\end{array}$ \\
\hline Overall & 197.21 & 23.05 & 181.54 & 18.71 & 172.44 & 18.47 & 164.18 & 15.92 \\
\hline
\end{tabular}

variance can be attributed to individual differences in the RT measures across subjects.

Table 2 contains the individual and overall means and standard deviations of the four subjects' RTs to the 20 combinations of signal frequency and intensity. It is noteworthy that the variability of each subject's response is considerably lower than that found in most simple RT experiments. Specifically, Woodworth and Schlosberg (1954) reported that the standard deviation of a highly practiced subject under the most ideal RT conditions is typically $10 \%$ to $13 \%$ of his mean RT. However, the standard deviations in Table 2 range from only $8 \%$ to $10 \%$ of the mean RTs. Since the variability in the RT measures is small, it follows that any mean differences among the conditions in our study are more likely to be reliable. $^{3}$

Figure 3 shows the individual RT-frequency functions for one subject, J.S., along with a separate RTfrequency function (dashed line) for data obtained

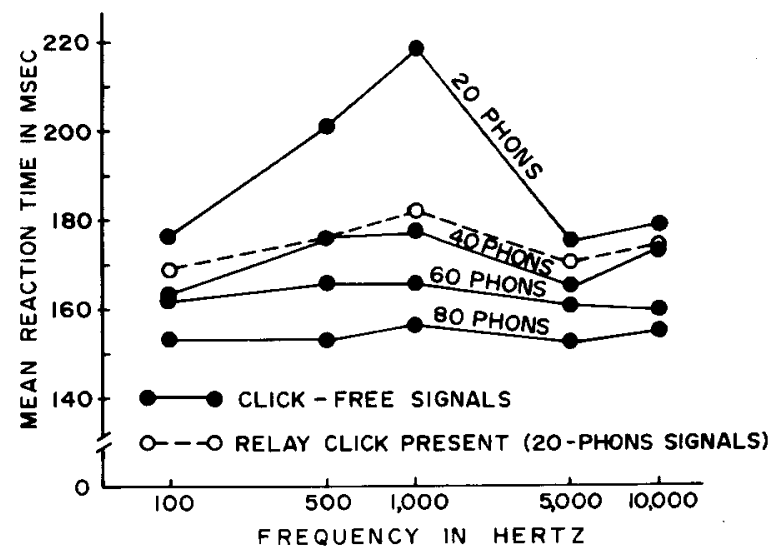

Figure 3. Mean reaction time as a function of stimulus frequency (Hz) at four levels of loudness (phons) for Subject J.S. The solid lines are for click-free signals, and the dashed line is for a click-present 20-phon condition. Each data point in the click-free conditions is the mean of 144 RT measures, whereas each point in the click-present condition represents 48 RT measures. 
when a relay, rather than the electronic switch, was used to gate the RT signals. This latter function was obtained at the 20-phon level for J.S. only. It may be seen that the response latencies to the 20-phon signals with click transients are comparable to those obtained in the 40-phon, click-free conditions. It appears that improperly gated signals can produce a RT-frequency function that is both flatter and lower (shorter mean RTs) than when the rise times are controlled by an electronic switch. Our purpose for including this relay-click condition in Experiment 1 will be discussed subsequently.

\section{Discussion}

The outcome of Experiment 1 provided only equivocal support for the conclusion, based on Chocholle's (1940) research, that there exists a straightforward relation between loudness and RT. In support of Chocholle's research, the relation between RT and equal loudness remained stable across the five stimulus frequencies at the 60- and 80-phon intensity levels. At 40- and 20-phon levels, however, this relationship breaks down; that is, the RT-frequency functions in our data were not flat. Specifically, RTs to the $1,000-\mathrm{Hz}$ tones at 20 and 40 phons were longer than RTs to the other four frequencies at the same levels of perceived intensity. This pattern of results is virtually identical with those obtained by Santee and Kohfeld (1977), thus making it unlikely that our present data are anomalous.

Alternatively, it could be suggested that our RT results at 40 and 20 phons are attributable to the relative steepness of the equal-loudness contours (see Figure 1) from which our RT signals were drawn. As noted previously, our earphone calibration procedures quite possibly resulted in loudness values at $100 \mathrm{~Hz}$ (especially at 20 phons) that were $12-16 \mathrm{~dB}$ stronger than the actual SPLs in the ear canal. Following this logic, since stronger signals yield more rapid RTs, could it be that, for example, the mean RT to the 20-phon, $100-\mathrm{Hz}$ signal in Figure 2 is spuriously low in comparison with the corresponding value at $1,000 \mathrm{~Hz}$ ? If so, this kind of thinking could be used to discredit some of our equal-loudness data and, consequently, to assert that some of our RT results provide no basis for rejection of Chocholle's original view that equal loudness yields equal RT. In defense of our procedures, it should be noted that we used the same set of calibrated earphones for signal presentation in both the equal loudness and the RT sessions. Thus, for example, the potential 12-16-dB difference between ear-canal intensity and earphonecoupler intensity for the same 20-phon signal at $100 \mathrm{~Hz}$ is "neutralized" when the physical characteristics of the tones are the same in both the equal-loudness matching and the RT tasks.

In our view, a more reasonable explanation for the discrepancy between our findings and Chocholle's for the weak-intensity signal levels is based on equipment problems encountered by Chocholle. As mentioned previously, he was unable to gate adequately the signals that were presented to his subjects by means of an electromagnetic earphone. If auditory RT signals are not gated by an electronic switch, highamplitude click transients can occur in conjunction with stimulus onset. A transient click, caused by the sudden onset of a tone, contains a sharply rising wave front of energy that excites a much greater array of nerve fibers than do pure tones (Richards, 1976). Physiological evidence also indicates that auditory nerve impulses are aroused more easily by sudden, click-like stimuli than by smooth, continuous tones (Wever, 1949). Based on these considerations, one might expect that click transients would be especially problematic for weak-intensity RT signals. This is because a relay click would not only increase the overall energy of a weak stimulus, but would also tend to equate the effective stimulus intensity of the RT signals across the various frequencies.

As noted previously, relay clicks were deliberately introduced into one of our 20-phon conditions in order to determine whether they would produce a departure from the other click-free, 20-phon conditions. Figure 3 reveals that the effects of the clicks were so pronounced that the click-present, 20-phon function resembles the click-free function at $\mathbf{4 0}$ phons. One might question just how loud the clicks sounded subjectively over the headphones. Consistent with Chocholle's account, our subject (J.S., the second author) also reported that any relay-click transient at signal onset was not even perceptible for the 20-phon signals, even though the electronic switch was replaced by a relay. Thus it appears that a click transient does not have to be heard by the subject in order for it to have a pronounced effect on reaction time. In view of this evidence, we conclude that weakintensity signals containing click transients will make a RT-frequency function spuriously lower (shorter mean RTs) and flatter (equating mean RTs) than when click-free signals are utilized.

In our view, the fact that equally loud stimuli do not always yield equal RTs is mainly a result of the difference between the temporal demands of the RT task and those required in equal loudness matching. Specifically, it has been proposed that the two necessary components in the RT response are signal detection and response initiation (Green \& Luce, 1971). This means that a highly practiced subject will initiate a response to the onset of a signal when a change (e.g., an increase) in the level of spontaneous neural activity in the auditory system has occurred. Stimulus discrimination is unnecessary in simple RT, since the subject is instructed to respond immediately when the "detector" notes a criterion change in the flow of neural impulses (see Luce \& Green, 1972, 1974, for a discussion of neural impulse models of 
auditory sensory detection). In loudness matching, however, the observer is required not only to detect a signal, but also to discriminate its sensory intensity with respect to some standard prior to making a decision about the point of subjective equality between the two stimuli. In other words, the detection component in RT is dependent upon the initial rate of increase of neural firing, whereas the corresponding discrimination component in loudness matching involves a subsequent analysis of the neural impulse flow that relies on temporal summation.

A variety of experiments can be cited in support of our contention that the estimation of loudness and the detection of a signal require different perceptual operations. Several investigators have shown that the sensation of loudness grows as stimulus duration increases. For example, Békésy (1967) found that the loudness of a tone develops throughout a period of $180 \mathrm{msec}$. Others have reported that the gradual growth of loudness may take as long as $600 \mathrm{msec}$ (Ekman, Berglund, \& Berglund, 1966), or even $1 \mathrm{sec}$ (Littler, 1965). Obviously, signal detection is completed much sooner than the time it takes for loudness to reach its peak amplitude. In fact, mean RT (involving both signal detection and response initiation) to the weakest signal in our experiment ( 20 phons at $1,000 \mathrm{~Hz}$ ) was only $273 \mathrm{msec}$. From a related perspective, neuroelectric recordings from the auditory nerve usually start with an abrupt "on" effect that is not preceded by a gradual buildup to peak amplitude that would result from the integration process typically associated with loudness (Zwislocki, 1960, 1969). At the cortical level, the auditory-evoked response also exhibits a sudden "on-off" response to stimulus presentations and terminations (Skinner \& Antinoro, 1971; Skinner \& Jones, 1968). We think that this initial, rapid "on" response to auditory signals corresponds to the latency of the detection component in simple RT. Indeed, the amplitude and latency of the "on" response are influenced by stimulus intensity (Schweitzer \& Tepas, 1974) and signal rise time (Skinner \& Jones, 1968); the latter two variables are also important determinants of simple RT (Santee \& Kohfeld, 1977).

There are certain characteristics of the equalloudness contours (Figure 1) and the RT-frequency functions (Figure 2) which also indicate some fundamental differences between loudness matching and RT processes, respectively. One predominant feature of the equal-loudness data is that stronger levels of stimulus intensity at 100 and $10,000 \mathrm{~Hz}$ were required to achieve equal loudness with the weaker, $1,000-\mathrm{Hz}$ standards. One way to account for the $\mathrm{V}$ shaped equal-loudness contours, which are especially apparent at the 20- and 40-phon intensity levels, is based on the neural events that underlie the perception of loudness. Specifically, it is hypothesized that the loudness of a stimulus results from the temporal summation of acoustic energy, as reflected by the number of neural impulses that are recruited (Troland, 1929; Wever, 1949; Zwislocki, 1960, 1969). In the present context, two sinusoidal stimuli were judged to be equally loud when the total number of integrated impulses was approximately the same for both auditory sensations over a sufficient period of time (see, also, Ross, 1968). However, the number of nerve fibers along the basilar membrane varies as a function of the stimulus frequency to be received. Wever (1949), for example, has estimated that the number of nerve fibers in the $1,000-\mathrm{Hz}$ region of the cochlea is approximately six times greater than those in either the extremely high- or low-frequency regions. This would explain why stronger levels of stimulus intensity were necessary in order to equate the total amount of neural activity from high- and lowfrequency tones with the corresponding amount of neural activity from the middle-frequency, $1,000-\mathrm{Hz}$ standard. Consequently, when the relatively stronger intensity 100 - and $10,000-\mathrm{Hz}$ tones were subsequently employed as RT signals, their detection was quite rapid in comparison with that of the $1,000-\mathrm{Hz}$ tones. As seen in Figure 2, this procedure resulted in RTfrequency functions at 20 and $\mathbf{4 0}$ phons which show progressive lengthening of mean RT until the peak slowness at $1,000 \mathrm{~Hz}$ is reached.

As stated previously, our data were consistent in part with Chocholle's; that is, equal-loudness matches did produce equal-RT measures at 60 and 80 phons. At least two possible reasons for this equivalence at the strong intensity levels can be offered. First, the equal-loudness contours, shown in Figure 1, reveal a diminishing effect of stimulus frequency at 60 and 80 phons. That is, the contours get flatter with increasing stimulus intensity, thus tending to reduce the differences in intensity among the five stimuli that are to be used as RT signals. Second, and perhaps more importantly, it is likely that increases in signal intensity eventually result in the equalization across frequencies of the rates of neural rise time at signal onset. In other words, the initial wave front of energy in the detector rises so rapidly, regardless of stimulus frequency, that the RT measures cannot register any differences among the neural events arising from different locations along the basilar membrane.

\section{PHASE 2: REACTION-TIME SCALES OF AUDITORY INTENSITY}

It would be inappropriate to conclude, based on the outcome of Experiment 1, that if RT and loudness are sometimes imperfectly correlated, then either RT measures or loudness estimates (or both) will generate an inferior, or perhaps inaccurate, scale of au- 
ditory intensity. The issue here is essentially a logical one-that is, the old problem of correlation and causation. Clearly, auditory stimulus energy is a causative (hence, correlative) physical dimension which underlies both the detection (RT) process and the discrimination (loudness) process, whereas the relation between these two resultant processes should be regarded as correlative only, at least until more evidence is available. Indeed, the issue of which kind of assessment, loudness or RT, provides a more valid (reliable, robust) scale of auditory intensity is a matter for empirical comparison. Accordingly, two constructive ways in which to address this issue are: (1) Can both RT measures and loudness estimates serve as valid scales of auditory intensity? (2) If so, how close is the parallel between these two scales; for example, can both scales be described by power exponents?

\section{Experiment 2}

The primary aim of Experiment 2 was to obtain a RT-intensity curve over the widest possible range of signal intensities at $1,000 \mathrm{~Hz}$. Basically, we wanted to know if this RT-intensity function could be described by a power function and, if so, whether the value of the power-function exponent would resemble those obtained when loudness-scaling procedures are employed.

\section{Method}

D.K., the senior author, served as the subject in this study. D.K. is a highly practiced subject, having had years of experience in RT experiments. His sensation level (SL) at $1,000 \mathrm{~Hz}$ is $20 \mu \mathrm{N} / \mathrm{m}^{2}$ (.0002 dynes $/ \mathrm{cm}^{2}$ ).

The RT signals were presented in 5-dB steps between $5 \mathrm{~dB}$ (re
SL) and $20 \mathrm{~dB}$, and in 10-dB steps between 20 and $110 \mathrm{~dB}$. The $110-\mathrm{dB}\left(63.5 \mathrm{dynes} / \mathrm{cm}^{2}\right)$ intensity level was the one beyond which further increases in intensity were painful. The RT paradigm and procedures were identical to those employed in Experiment 1.

\section{Results and Discussion}

Figure 4 portrays mean RT as a function of both signal intensity in decibels and loudness level in sones. The results of Experiment 2 are the immediate focus of concern; the other three RT intensity functions will also be discussed subsequently. In Experiment 2, each data point represents the mean of 48 RT measures. In each case, the standard deviation was between $8 \%$ and $9 \%$ of its mean. The sone-scale values at the top of Figure 4 are positioned in accordance with their corresponding decibel values (on the lower abscissa), as tabled in Stevens (1956). ${ }^{4}$

Figure 4 also shows mean RT from three other experiments, plotted as a function of stimulus intensity in dB, SPL (McGill, 1961; Murray \& Kohfeld, 1965), and $\mathrm{dB}, \mathrm{SL}$ (Chocholle, 1940). ${ }^{5}$ In general, Figure 4 reveals the well-known inverse relation between stimulus intensity and simple auditory reaction time. Our next step was to specify the nature of this relationship, that is, to determine whether RT was a power function of auditory stimulus energy.

\section{DETERMINATION OF THE POWER EXPONENT}

It is well known that the general expression for the loudness function is the power equation

$$
\mathbf{L}=\mathbf{k}(\mathrm{SP})^{\mathbf{n}} \text {, }
$$

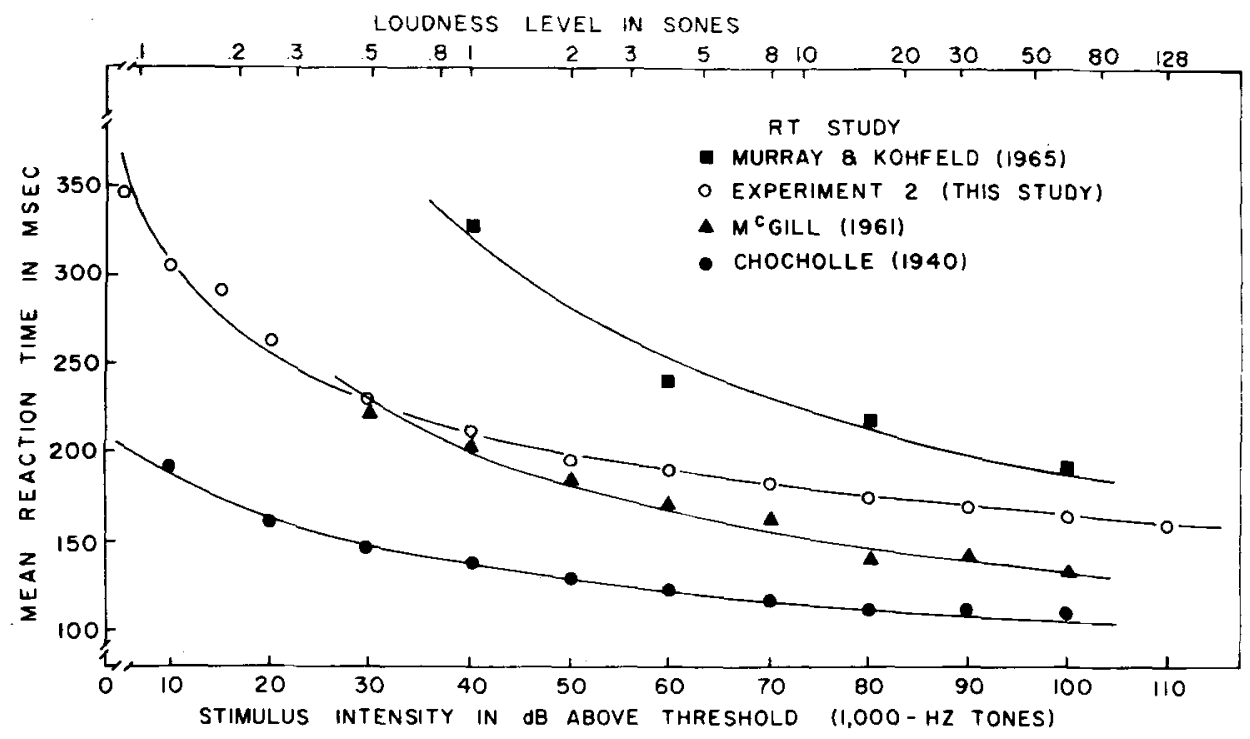

Figure 4. Relation between stimulus intensity (lower abscissa), londness level (upper abscissa), and mean reaction time to 1,000-Hz tones. RT measures in each data point are as follows: (1) Murray and Kohfeld (1965), 120 from 10 unpracticed subjects; (2) Experiment 2 (present), 48 from one practiced subject; (3) MeGill (1961), 20 from one "typical" practiced subject; and (4) Chocholle (1940), at least 100 from one highly practiced subject. 
where $\mathrm{L}$ is loudness, $\mathrm{SP}$ is sound pressure, $\mathrm{k}$ is the intercept, and $\mathrm{n}$ is the exponent. The generally accepted value of $n$ in Equation 1 is .6 (Marks, 1979). When $L$ is measured in sones (see upper abscissa in Figure 4; also, Footnote 4) and SP in dynes $/ \mathrm{cm}^{2}$, the value of $\mathrm{k}$ is 10.45 (see Scharf, 1978, pp. 188-191).

Suppose that auditory reaction time was also a simple power function of sound pressure, such that

$$
\mathrm{RT}=\mathrm{k}(\mathrm{SP})^{\mathrm{n}} .
$$

Employing Equation 2, if one were to compute the exponent based on the raw mean RT measures from, for example, Chocholle's experiment (see Figure 4), the absolute value of $n$ would be .05 , which is only $1 / 12$ th the size of the loudness exponent of .6. The problem is that overall RT measures contain a motor or "nonsensory" component which obscures the relation between stimulus intensity (sound pressure) and the actual "sensory" (detection) component. Accordingly, many RT investigators have assumed some lower limit on RT beyond which the RT latency cannot decrease, despite further increases in auditory stimulus intensity. Based on Chocholle's data, Woodworth and Schlosberg's (1954) estimate of this minimum RT was $100 \mathrm{msec}$. Subsequent investigators also used $100 \mathrm{msec}$ in their theoretical analyses; see, for example, Grice, 1968; Kohfeld, 1969a; and more recently, Scharf, 1978. On the other hand, Luce and Green (1972) chose a minimum RT value of $105 \mathrm{msec}$, which is 5 msec lower than the mean RT to the strongest signal $(100 \mathrm{~dB})$ in Chocholle's experiment (see Appendix). The important point is that a more acceptable way to explore the value of the power exponent in reaction-time work is to revise Equation 2 as follows:

$$
\mathrm{RT}-\mathrm{r}=\mathrm{k}(\mathrm{SP})^{\mathrm{n}} \text {, }
$$

where $r$ is the "residual latency" (Luce \& Green's term), the "nonsensory factor" (Scharf's term), or, more traditionally, the "irreducible minimum RT" (Woodworth \& Schlosberg's term). Using Equation 3, if we assume that $r=100 \mathrm{msec}$, the absolute value of the power exponent for Chocholle's data is .22 , as compared with $\mathrm{n}=.05$ when no constant is subtracted (Equation 2). Although the absolute size of $n$ has increased, it still does not approximate the loudness exponent of .6, and appears to depend rather heavily on the value of $r$ in Equation 3.

There are at least three major disadvantages in making a priori assumptions about the value of $r$ in Equation 3. First, it cannot be estimated directly and therefore is hypothetical. Second, as noted by Luce and Green (1972, pp. 40-41), changing $r$ by only $5 \mathrm{msec}$ has a sizable effect on the power exponent. Thus, for example, if $r=100 \mathrm{msec}$ for Chocholle's data, $\mathrm{n}=.22$, whereas if $\mathrm{r}=105 \mathrm{msec}, \mathrm{n}$ increases to .28. Third, the subject variables of practice, incentive, and attentiveness to the RT task probably contribute heavily to the value of $r$. Thus, we suggest that $r$ should be regarded as a variable across experiments rather than as a constant value.

Because of difficulties in making initial estimates of the nonsensory component in auditory RT tasks, an alternative approach is to make no prior assumptions about the exact value of $r$. In this vein, let us begin by moving $r$ to the right side of Equation 3, yielding

$$
\mathbf{R T}=\mathbf{r}+\mathbf{k}(\mathrm{SP})^{\mathrm{n}} .
$$

If we now take the derivative with respective to SP, we get

$$
\frac{\mathrm{dRT}}{\mathrm{dSP}}=\mathbf{n k}(\mathrm{SP})^{\mathrm{n}-1}
$$

In Equation 5, the derivative $\mathrm{dRT} / \mathrm{dSP}$ is negative. The next step is to rewrite Equation 5 as follows:

$$
\log \left|\frac{\mathrm{dRT}}{\mathrm{dSP}}\right|=\log |\mathbf{n k}|+(\mathrm{n}-1) \log \mathrm{SP} .
$$

The major advantage of Equation 6 is that it is independent of $r$.

There are two steps in applying Equation 6 to a set of RT data: (1) Estimate dRT/dSP at all values of SP (stimulus intensity) that are used in a particular RT experiment; and (2) plot each log $|\Delta R T / \Delta S P|$ against the corresponding log SP value for each intensity level used in this particular RT experiment. It follows that if RT is a power function of SP, the graph obtained in Step 2 should yield a straight line, the slope of which is $n-1$. Thus, for example, if $n=$ -.30 , the slope of the line in Step 2 would be -1.30 . The computations indicated in Step 1 can easily be performed with a desk calculator, as shown in the appendix.

\section{Results and Discussion}

Figure 5 shows the outcome of the analyses described in Steps 1-2, as applied to the data from our Experiment 2, as well as to those from five previous RT investigations. Each panel in Figure 5 contains the value of the power exponent $(\mathrm{n})$, the intercept $(\mathrm{k})$, the nonsensory component $(r$, in $\mathrm{msec}$ ), and the strength of the linear relation among the data points $\left(R^{2}\right) .{ }^{6}$ Since $R T$ is inversely related to stimulus intensity, the values of $\mathbf{n}$ are negative. In view of the large values of $R^{2}$ in all panels of Figure 5, as well as the obvious linearity of the $\log -\log$ plots, it may be concluded that the latency, in milliseconds, of the sensory component of reaction time decreases as a power 

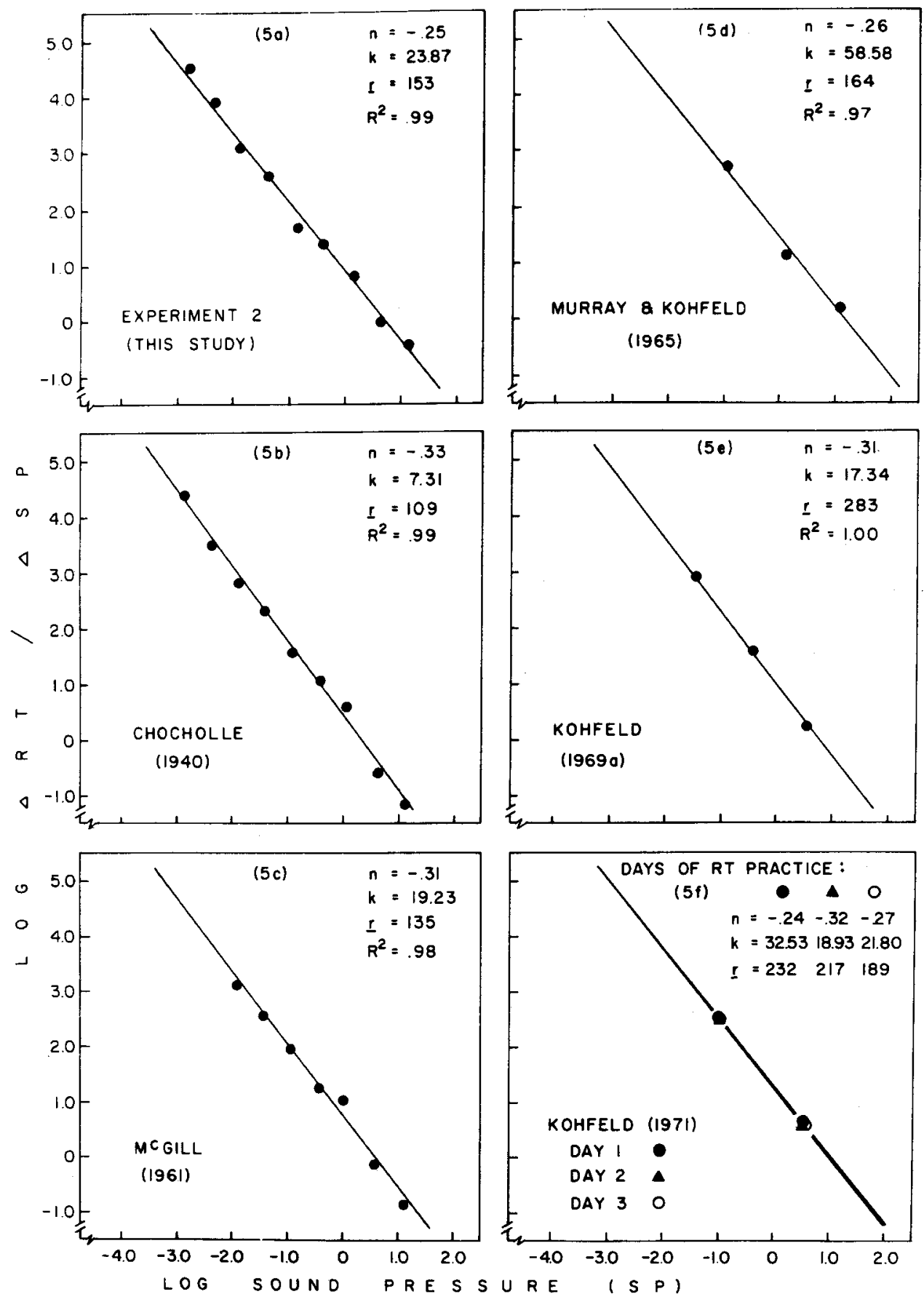

Figure 5. Power functions for RT intensity curves (at 1,000 Hz) from six different experiments. See the appendix for clarification of the units on each axis. In Figure 5a, only the data points between 10 and $100 \mathrm{~dB}$ at 10-dB intervals (from our present Experiment 2) are plotted in order to provide a direct comparison with Chocholle's classic data (Figure 5b) at these same values. Listed in each panel are the values of the power exponent ( $n$ ), the intercept (k), the nonsensory or residual component (r), and the variance accounted for among the data points $\left(R^{2}\right)$. Note that the exponent $(n)$ is relatively stable across experiments, whereas the nonsensory factor ( $r$ ) varies considerably.

function of sound pressure, in dynes $/ \mathrm{cm}^{2}$. Moreover, all six experiments reveal similar power exponents; the smallest exponent is - .24 (Figure 5f, Day 1), and the largest value is -.33 (Figure $5 \mathrm{~b}$ ). The average value of $n$ is -.29 .
The values of $r$ in Figure 5 deserve additional consideration. Recall that the value of $\mathrm{n}$ was obtained from Equation 6 . The value of $k$ could also be obtained from Equation 6, and, along with the value of $n$, could then be used in Equation 4 to determine $r$. 
However, small errors in the computation of log |nk $\mid$ are magnified by the exponentiation required to obtain $\mathrm{k}$ from Equation 6 . We obtained more accurate results by using the value of $\mathbf{n}$ obtained from Equation 6 , and by use of regression analysis as before, obtaining values for both $\mathrm{k}$ and $\mathrm{r}$ from Equation $4 .^{7}$ We were especially curious as to how closely our estimate of $r$ for Chocholle's data (Figure 5 b) would resemble the 100 -msec value suggested by Woodworth and Schlosberg (1954), or perhaps the 105-msec estimate used by Luce and Green (1972). The obtained value of $109 \mathrm{msec}$ reinforced our belief that Equation 6 generates estimates of $n$, which, in turn, yield reasonable estimates of $r$ from Equation 4. In other words, Chocholle's residual RT value of $r=109 \mathrm{msec}$ is consistent with the very slow reduction in mean RT at strong intensity levels - that is, RT decreased from $112 \mathrm{msec}$ at $80 \mathrm{~dB}$ to $110 \mathrm{msec}$ at $100 \mathrm{~dB}$-and by our present inference, continued increases in signal intensity beyond $100 \mathrm{~dB}$ would not have yielded corresponding decreases in $\mathrm{RT}$ below our computed value of $109 \mathrm{msec}$, the "irreducible minimum" RT for Chocholle's data. The estimates of $r$ in the remaining panels of Figure 5 are also reasonable when one considers the circumstances that prevailed in each respective $\mathrm{RT}$ experiment. Figures $5 \mathrm{a}$ and $5 \mathrm{c}$ contain data for one practiced subject in each case. In Figure 5a, the subject (D.K.) reported that $153 \mathrm{msec}$ is a good estimate of his irreducible minimum RT; that is, response latencies lower than this border on response anticipations rather than true RTs. In Figure 5e, the RT data are from unpracticed subjects performing in a condition which tends to slow overall RT (90-dB ready signals; see Kohfeld, 1969 b for details), which accounts for the elevated nonsensory component, $r=283$. To obtain some idea of whether r decreases with practice, Figure $5 f$ shows the data from moderately practiced subjects as they progress through three daily RT sessions (Kohfeld, 1971). Note that on Day 1, r $=232$; on Day 2, r =217; and on Day 3, $r=189$. Finally, Figure $5 d$ shows data from unpracticed subjects who performed in a RT condition which tends to produce rapid responses (preexposure to a very soft tone; see Murray \& Kohfeld, 1965 , for details); their value of $r$ is $164 \mathrm{msec}$. In general, the nonsensory component $r$ appears to depend rather heavily on practice, task variables, and individual differences.

Recently, Marks (1974) has proposed that there are two separate power functions relating loudness to stimulus intensity, each of which has a different exponent. Marks suggested that a distinction be made between what he termed a Type I scale of loudness, whose data are based on ratio-scaling procedures (e.g., magnitude estimation), and a Type II scale, in which data are generated with interval-scaling procedures (e.g., interval estimation). He presented con- siderable evidence in support of his conclusion that the power exponent for the Type I scale of loudness is about .6, whereas that for the Type II scale is roughly .3 (see Tables 1 and 2 in Marks, 1974). In a brief review of two RT experiments (Chocholle's and McGill's), Marks also noted that the power-function exponent relating reaction speed $(1 / \mathrm{RT})$ to sound pressure is about .3, a value which is similar to the exponent obtained from the Type II scale of loudness. Of course, if reaction time (RT) is plotted as a function of Type II loudness (based on interval-scaling procedures), the exponent should be about -.3. In the main, the power exponents listed in Figure 5 (average value of -.29 ) are consistent with Marks' contention that $\mathrm{RT}$ and sound pressure are related by a power function whose exponent is on the order of -.3. Moreover, it is intriguing to note that the RT measure, at least at $1,000 \mathrm{~Hz}$, shows a relation to auditory stimulus intensity (in dynes $/ \mathrm{cm}^{2}$ ) which is analogous to the Type II scale of loudness that is based on interval-scaling procedures.

Although the RT intensity functions from the experiments depicted in Figure 4 are somewhat similar in shape, they are definitely not overlapping. This is inevitable, simply because the variables of practice, as well as procedural differences, can easily account for large differences among the RT curves. What is impressive is that the power exponents across experiments (see Figure 5) are quite similar, despite the variations in practice, methods of stimulus presentation, and individual differences. In this respect, if one were to compare the relative merits of RT scaling procedures with those of loudness scaling, the RT measure might provide a more robust scale of auditory stimulus intensity because the exponents of the RT intensity functions are less susceptible to experimental and individual differences. However, despite the stability of the power exponent across RT experiments, the puzzle remains concerning its absolute size, which appears to be one-half of the size of the conventional loudness exponent of .6 .

\section{SUMMARY AND CONCLUSIONS}

One major impetus for the present research was our belief that "sounds that differ in frequency and pressure, but appear equal in loudness, give the same reaction time'" (Marks, 1974, p. 372). Our intent was to verify this conclusion and then to proceed with subsequent work in which we intend to model the RT distributions at different signal intensities and frequencies. Instead, we found that equal loudness did not yield equal RT at weak intensity levels. In order to explain these results, we have proposed that signal detection and loudness discrimination involve different perceptual operations, particularly with respect to their temporal dissimilarity. Since these two pro- 
cesses are the necessary initial components in simple RT and loudness matching, respectively, we cannot find a logical reason why equal-loudness judgments should produce signal intensities that will, in turn, generate equal RTs.

The classic experiment against which our data must be compared is Chocholle's (1940), in which he found that equal loudness did produce equal RT over the entire range of stimulus intensities in his experiment. However, Chocholle unavoidably included click transients in his RT signals. In our Experiment 1 , we compared the RT data from click-free signals with those from a condition in which relay clicks were introduced. It was found that clicks produced an approximately equal RT function at a 20 phon intensity level, whereas click-free signals at this intensity did not. In general, the fact that loudness and RT were imperfectly related when click-free 20and 40-phon signals were employed across all four subjects led us to propose that the neural events which underlie signal detection (RT) are different from those in loudness discriminations (equal loudness matching). However, when either signal intensity is increased (e.g., 60- or 80-phon click-free signals), or when clicks are included in weak signals (i.e., 20 phons), the equal-loudness with equal-RT relation is restored. These latter results are consistent with the interpretation that either strong RT signals or weak ones with clicks result in the equalization of initial, "neural" rise times in the signals across frequencies, thus yielding equal RT. It is apparent that the differences between detection and loudness mechanisms may be seen most clearly when click-free, weak-intensity signals are employed.

In our view, the most enduring influence of Chocholle's work will be the continued efforts to use his RT measures as a scale of auditory intensity. In this endeavor, it is not essential for equal loudness to produce equal reaction time. Rather, the important point is to compare RT scales with corresponding loudness scales, based on the same sound-pressure values. Accordingly, in this paper we introduced a computational procedure which allows an investigator to compute the value of the power exponent (n) for RT intensity functions, free of initial assumptions about the exact value of a nonsensory or "residual" factor ( $r$ ) that is usually subtracted from RT measures before a scale is constructed. The result was a fairly consistent estimate of $\mathbf{n}$ across a variety of different RT experiments. Moreover, the value of $r$ varied predictably, based on individual differences and levels of RT practice. It may be concluded that the sensory component in RT measures decreases (becomes faster) as a power function of corresponding increases in sound pressure. Another way of stating this is that the sensory component in RT varies as a function of stimulus intensity, whereas the nonsensory component varies primarily in accordance with subject-relevant variables. At this stage of our work on loudness and reaction time, the absolute value of the "sensory-detection" power exponent is about .3, which compares favorably with the exponent for interval scales of loudness (Marks, 1974), but is only one-half the size of the .6 exponent commonly assumed for ratio scales of loudness.

The next article in this series on loudness and reaction time will deal with an analysis of the RT distributions which are generated from different signal intensities and frequencies. Our models of the RT process will be based on the assumption that observed RT distributions represent a convolution of two component random variables: one of these reflects the detection (sensory) process $\left(t_{d}\right)$, and the other has to do with the response or "residual" (nonsensory) latency $\left(t_{r}\right)$. We have deconvolved $t_{d}$ and $t_{r}$ from empirical RT distributions, and intend to use the shapes of the detection-latency densities to help in the identification of underlying processes.

\section{REFERENCES}

BÉ Késy, G. Von. Sensory inhibition. Princeton, N.J: Princeton University Press, 1967.

Beranek, L. L. Acoustic measurements. New York: Wiley, 1949.

Cattell, J. M. The influence of the intensity of the stimulus on the length of the reaction time. Brain, 1886, 8, 512-515.

Chосноle, R. Variation des temps de réaction auditif en fonction de l'intensité à diverses fréquences. Année Psychologique, 1940, 41, 65-124.

Exman, G., Berglund, B., \& Berglund, U. Loudness as a function of the duration of auditory stimulation. Scandinavian Journal of Psychology, 1966, 7, 201-208.

Fletcher, H., \& Munson, W. A. Loudness, its definition, measurement and calculation. Journal of the Acoustical Society of America, 1933, 5, 82-108.

Green, D. M., \& Luce, R. D. Detection of auditory signals presented at random times: III. Perception \& Psychophysics, $1971,9,257-268$.

Grice, G. R. Stimulus intensity and response evocation. Psychological Review, 1968, 75, 359-373.

Hagan, B. J. Preparatory factors in simple reaction time. Master's thesis, Southern Illinois University at Edwardsville, 1980.

Hellman, R. P., \& Zwislock I, J. J. Loudness determination at low sound frequencies. Journal of the Acoustical Society of America, 1968, 43, 60-64.

KOHFELD, D. L. Effects of the intensity of auditory and visual ready signals on simple reaction time. Journal of Experimental Psychology, 1969, 82, 88-95. (a)

KOHFELD, D. L. Effects of ready-signal intensity and intensity of the preceding response signal on simple reaction time. American Journal of Psychology, 1969, 82, 104-110. (b)

KoHFELD, D. L. Simple reaction time as a function of stimulus intensity in decibels of light and sound. Journal of Experimental Psychology, 1971, 88, 251-257.

Kristoffe RSON, A. B. Low-variance stimulus-response latencies: Deterministic internal delays? Perception \& Psychophysics, 1976, 20, 89-100.

LITTLE R, T. S. The physics of the ear. New York: Macmillan, 1965.

Luce, R. D., \& Green, D. M. A neural timing theory for response times and the psychophysics of intensity. Psychological Review, 1972, 79, 14-57.

LuCE, R. D., \& Green, D. M. Detection, discrimination, and recognition. In E. C. Carterette \& M. P. Friedman (Eds.), Handbook of perception (Vol. 2). New York: Academic Press, 1974.

Marks, L. E. On scales of sensation: Prolegomena to any future 
psychophysics that will be able to come forth as science. Perception \& Psychophysics, 1974, 16, 358-376.

Marks, L. E. A theory of loudness and loudness judgments. Psychological Review, 1979, 86, 256-285.

McGill, W. J. Loudness and reaction time. Acta Psychologica, 1961, 19, 193-199.

Molino, J. A. Pure-tone equal-loudness contours for standard tones of different frequencies. Perception \& Psychophysics, 1973, 14, 1-4.

Murray, H. G., \& Kohfeld, D. L. Role of adaptation level in stimulus intensity dynamism. Psychonomic Science, 1965, 3, 439-440.

Pí́ron, $\mathbf{H}$. Nouvelles recherches sur l'analyse du temps de latence sensorielle et sur la loi qui relie le temps à l'intensité d'excitation. Année Psychologique, 1920, 22, 58-142.

RESTLE, F. Psychology of judgment and choice. New York: Wiley, 1961.

RichaRDS, A. M. Basic experimentation in psychoacoustics. Baltimore: University Park Press, 1976.

Robinson, D. W., \& Dadson, R. S. A re-determination of the equal loudness relations for pure tones. British Journal of Applied Physics, 1956, 7, 166-181.

Ross, S. Matching functions and equal-sensation contours for loudness. Journal of the Acoustical Society of America, 1967 , 42, 778-793.

Ross, S. Impedance at the eardrum, middle-ear transmission, and equal loudness. Journal of the Acoustical Society of America, 1968, 43, 491-505.

Santee, J. L., \& Kohfeld, D. L. Auditory reaction time as a function of stimulus intensity, frequency, and rise time. Bulletin of the Psychonomic Society, 1977, 10, 393-396.

Scharf, B. Loudness. In E. C. Carterette \& M. P. Friedman (Eds.), Handbook of perception (Vol. 4). New York: Academic Press, 1978.

Schweitze R, P. K., \& Tepas, D. T. Intensity effects of the auditory evoked brain response to stimulus onset and cessation. Perception \& Psychophysics, 1974, 16, 393-400.

Srinnen, P. H., \& Antinoro, F. The effects of signal rise time and duration on the early components of the auditory evoked cortical response. Journal of Speech and Hearing Research, $1971,14,552-558$.

Skinner, P. H., \& Jones, H. C. Effects of signal duration and rise time on the auditory evoked potential. Journal of Speech and Hearing Research, 1968, 11, 301-306.

Steinberg, J. C., \& Munson, W. A. Deviations in loudness judgment of 100 people. Journal of the Acoustical Society of America, 1936, 8, 71-80.

Stevens, S. S. Calculation of the loudness of complex noise. Journal of the Acoustical Society of America, 1956, 28, 807-832.

Stevens, S. S., \& Davis, H. Hearing: Its psychology and physiology. New York: Wiley, 1938.

Troland, L. T. The psychophysiology of auditory qualities and attributes. Journal of General Psychology, 1929, 2, 28-58.

WEVER, E. G. Theory of hearing. New York: Wiley, 1949.

Woodworth, R. S., \& Schlosberg, H. Experimental psychology. New York: Holt, 1954.

WundT, W. Grundzuge der physiologischen psychologie (2nd ed.). Leipzig: Engelman, 1974.

Zwislocki, J. Theory of temporal auditory summation. Journal of the Acoustical Society of America, 1960, 32, 1046-1060.

Zwislocki, J. Temporal summation of loudness: An analysis. Journal of the Acoustical Society of America, 1969, 46, 431-441.

\section{NOTES}

1. A French-to-English translation of Chocholle's article has been provided to the authors by Veronique Zaytzeff, Department of Foreign Languages, Southern Illinois University at Edwardsville.

2. Actually, Fletcher and Munson (1933) used calibrated telephone receivers (headphones) to deliver tones to their listeners.
However, they converted their earphone data to corresponding free-field measures, as follows: "In order to reduce the data . . to those which one would obtain if the observer were listening to a free wave and facing the source, we must obtain a field calibration of the telephone receivers used in the loudness comparisons"' (p. 87). Subsequently, on pp. 87-91 they describe how their earphone data were free-field calibrated, and how the equal-loudness contours on pp. 90-91 (see Figures 3 and 4) were based on data converted from earphone measures to free-field conditions. Thus, Robinson and Dadson (1956) cite Fletcher and Munson's data as "the first set of contours for free-field conditions" (p. 166), and reproduce Fletcher and Munson's equal-loudness contours as the original open-field data against which their own free-field curves should be compared (see Figures 8 and 14 in Robinson \& Dadson, 1956). Similarly, Ross (1967) states that "Fletcher and Munson ... employed binaural listening through earphones that were calibrated against free-field tones of known intensity" (p. 786). Richards (1976) also notes that Fletcher and Munson used free-field techniques. In contrast, Stevens and Davis (1938) leave us with the impression that Fletcher and Munson published only earphone data; that is, no mention is made of the calibration conversion to freefield measures (see Figures 44 and 45 on pp. 123-125 in Stevens and Davis). More recently, Scharf (1978) reproduced Stevens and Davis' Figure 45, and also reported that Fletcher and Munson's contours (as described in Stevens and Davis) were generated from earphone listening. However, it seems clear that Fletcher and Munson's objective was to present equal-loudness contours that would be obtained with open-field methods of signal presentation. This conclusion is certainly consistent with Robinson and Dadson's interpretation of Fletcher and Munson's research.

3. Other investigators have also reported exceptionally small RT standard deviations when their subjects have reached a high level of training (e.g., Kristofferson, 1976). In addition to the highly practiced state of our subjects, we initially thought that the use of the Donders $C$ paradigm helped to reduce variability in the RT measures. Recently, however, Hagan (1980) found that the RT means and standard deviations were quite similar when a variableforeperiod procedure was compared with the Donders $C$ paradigm, using the same signal intensities and the same subjects at the highest possible levels of training. Although, in both RT paradigms, the subject must detect a signal before initiating a response, the principal task demand in the variable-foreperiod method is one of temporal uncertainty as to when the signal will occur, whereas with the Donders $\mathrm{C}$ method the main problem is signal uncertainty (whether or not the signal will occur on a given trial). It now appears that extensive practice with these two RT paradigms yields comparable RT means and standard deviations.

4. The definition of phons and sones is discussed in Stevens (1956); see, especially, Appendix 1, which also contains a complete table relating phon and sone values. Since all of the tones plotted in our Figure 4 are at $1,000 \mathrm{~Hz}$, their values in $\mathrm{dB}$ re $20 \mu \mathrm{N} / \mathrm{m}^{2}$ $\left(.0002\right.$ dynes $\left./ \mathrm{cm}^{2}\right)$, called sound pressure level (SPL), are identical with corresponding phon values. According to Stevens, 1 sone $=\mathbf{4 0}$ $\mathrm{dB}=40$ phons, at $1,000 \mathrm{~Hz}$.

5. Figure 4 reveals that Chocholle's RT intensity function is considerably lower (faster mean RTs) than the ones obtained by McGill and in our Experiment 2, even though all three studies employed a highly practiced subject. In our experience, it is impossible to generate "true" RTs as rapid as those reported by Chocholle, even if click transients are present in the RT signals. One possible explanation is that the Hipp Chronoscope used by Chocholle began timing slightly after the relay-contact closure which initiated the tone in the electromagnetic headphone; that is, the tone came on some $20-30$ msec prior to the start of the chronoscope, perhaps due to electromechanical lags in the chronoscope mechanism itself.

In addition, Chocholle reported a mean $R T$ measure at $0 \mathrm{~dB}$, SL. Just how his subjects could even respond very consistently to a threshold-level tone is unclear to us, unless the signal contained a click transient. We did not plot Chocholle's lowest data point in our Figure 4 (RT $=402 \mathrm{msec}$ ) because of its radical de- 
parture from the general shape of the RT intensity function between 10 and $100 \mathrm{~dB}$. Similarly, McGill's lowest data point at $20 \mathrm{~dB}$, even though ordinarily detectable, was omitted because of its sudden increase from the 30 - to 100 -dB function ( $R T=345 \mathrm{msec}$ ). The data from our Experiment 2 provide the most recent portrayal of the RT intensity function at $1,000 \mathrm{~Hz}$, taken over a wide range of clearly detectable RT signals.

6. Even though Chocholle's data were probably influenced by click transients, they did show, as expected, the typical inverse relation between signal intensity and RT, and a power exponent similar to those of the other five exponents shown in Figure 5 in which click-free signals were utilized. To reiterate and clarify, while click transients may contribute to a spurious relation between loudness and RT across frequencies, they will not necessarily change the value of the power-function exponent at a specific frequency, for example, at $1,000 \mathrm{~Hz}$.

7. Thanks are extended to $\mathbf{R}$. Duncan Luce for his extensive collaboration in the development of this latter procedure, although we retain responsibility for the outcomes of the analyses reported in Figure 5.

\section{APPENDIX}

In this appendix, we illustrate how the data points that are plotted in Figure 5 were calculated. In Table 1A is an example for Chocholle's Subject One, at $1,000 \mathrm{~Hz}$ (Chocholle, 1940, Table A, p. 90); these data are plotted in Figure $5 b$.
Column 1 indicates intensity level in decibels, and Column 2 shows mean reaction time (MRT), in milliseconds, at each intensity level. Column 3 indicates the corresponding sound pressure values in dynes $/ \mathrm{cm}^{2}$. Column 4 shows the changes in reaction time $(\Delta R T)$ from one intensity level to the next: e.g., $193-161=32 ; 161-148=13$, etc. Column 5 displays corresponding changes in sound pressure: $.002-.000635=.001365 ; .00635-.002=.00435$, etc. Next, Column 6 is the sound pressure midpoints between each intensity level: e.g., $.000635+.002=.002635 / 2=.001318$; $.002+.00635=.00835 / 2=.004175$, etc. Column 7 is the ratio of $\triangle R T$ (Column 4) over $\triangle$ SPL (Column 5); e.g., 32/ $.001365=23,443.2,13 / .00435=2,988.51$, etc. Finally, Column 8 is the log of each value in Column 7 , and Column 9 is the $\log$ of each value in Column 6 . The values in Column 9 are plotted on the abscissa in Figure 5b, and the corresponding values in Column 8 are represented on the ordinate.

We have available a computer program which provides rapid computation of values in Columns 4-9, and which also plots the graphs that are shown in Figure 5. The program requires only the values in Column 2 (mean RT in msec), and the corresponding values in Column 3 (sound pressure in dynes $/ \mathrm{cm}^{2}$ ). Based on the value of $\mathbf{n}$ obtained from Equation 6, our program then applies Equation 4 to compute the values of $r$ and $k$. Of course, $r$ (the "nonsensory" component) may then be subtracted from the reactiontime power equation (Equation 3).

Table 1A

\begin{tabular}{ccccccccc}
\hline Column 1 & Column 2 & Column 3 & Column 4 & Column 5 & Column 6 & Column 7 & Column 8 & Column 9 \\
\hline 10 & 193 & .000635 & 32 & .001365 & .001318 & $23,443.2$ & +4.37 & -2.880 \\
20 & 161 & .002000 & 13 & .004350 & .004175 & $2,988.51$ & +3.48 & -2.379 \\
30 & 148 & .006350 & 9 & .013650 & .013175 & 659.3406 & +2.82 & -1.880 \\
40 & 139 & .020000 & 9 & .043500 & .041750 & 206.8966 & +2.32 & -1.379 \\
50 & 130 & .063500 & 6 & .136500 & .131750 & 43.95604 & +1.64 & -.880 \\
60 & 124 & .200000 & 6 & .435000 & .417500 & 13.79310 & +1.14 & -.379 \\
70 & 118 & .635000 & 6 & 1.36500 & 1.31750 & 4.395604 & +.643 & +.120 \\
80 & 112 & 2.00000 & 1 & 4.35000 & 4.17500 & .229885 & -.638 & +.621 \\
90 & 111 & 6.35000 & 1 & 13.6500 & 13.1750 & .073260 & -1.14 & +1.120 \\
100 & 110 & 20.0000 & & & & & & \\
\hline
\end{tabular}

(Received for publication June 7, 1979; revision accepted March 25, 1981.) 